\title{
Dana Desa dan Respon Masyarakat Terhadap Manfaatnya di Nagari Sungai Tarab
}

\author{
Hanifa Fadilla, Suryanef \\ Prodi Pendidikan Pancasila dan Kewarganegaraan \\ Universitas Negeri Padang \\ E-mail: hanifafadilla1@gmail.com
}

\section{ABSTRAK}

Artikel ini bertujuan untuk mendeskripsikan mekanisme pengelolaan dana desa di Nagari Sungai Tarab, respon masyarakat terhadap manfaat dana desa di Nagari Sungai Tarab, dan permasalahan apa yang ditemukan dalam pengelolaan dana desa di Nagari Sungai Tarab. Penelitian ini dilakukan di nagari Sungai Tarab, Kecamatan Sungai Tarab. Metode penelitian dilakukan melalui pendekatan kualitatif deskriptif dengan menggunakan data primer dan sekunder yang diolah secara deskriptifkualitatif. Informan penelitian adalah tokoh masyarakat, kepala desa serta masyarakat Nagari Sungai Tarab. Teknik pengumpulan data pada penelitian ini menggunakan wawancara dan studi dokumntasi. Uji keabsahan data menggunakan teknik trianggulasi data. Teknik analisis data melalui tiga alur kegiatan yaitu mereduksi data, display data dan menarik kesimpulan dengan melakukan verivikasi. Hasil penelitian menunjukkan dana desa di Nagari Sungai Tarab masih mengalami beberapa kendala dalam penyalurannya seperti terlambatnya Musyawarah Perencanaan Pembangunan ditambah dengan masih rendahnya swadaya masyarkat yang kurang terhadap pembangunan yang sudah dibuat, kurangnya informasi langsung kepada masyarakat mengenai transparasi penggunaan dana desa, pemanfaatan yang lebih kepada bidang pembangunan, kurang dalam meningkatkan perekonomian masyarakat, ditambah lagi dengan sumber daya manusia yang kurang dalam mengelola dana desa.

Kata Kunci: pengelolaan, Dana Desa, pemerintah Nagari

\section{ABSTRACT}

This article aims at describing the management mechanisms of village funds in Nagari Sungai Tarab, public's response to the benefits of village funds and dicsribing what problems are found in the management of village funds in Nagari Sungai Tarab. This research was conducted in the Nagari Sungai Tarab, sub-district Sungai Tarab. The method of research is conducted through a qualitative and descriptive approach by using the primary and secondary data that is processed in a qualitative descriptive. The research informant is a public figure, neighbourhood and also a citizen of Nagari Sungai Tarab. The technique of collecting data on this research uses interviews and doctoral studies. Test the validity of data using the data trianggulation technique. Data analysis techniques through three threads of activity is reducing data, display data and draw conclusions with verification. The results of the study 
showed that village funds in Nagari Sungai Tarab still experienced some obstacles in its distribution such as the delay of development planning deliberation of the lack of nongovernmental community that is less on development That has been made, the lack of direct information to the public about the transparency of the use of village funds, utilization of more to the field of development, less in improving the community economy, coupled with the lack of resources People when managing village funds.

Keywords: management, village funds, local government

\section{PENDAHULUAN}

Pembahasan mengenai dana desa sekarang ini menjadi isu yang sedang hangat diperbincangkan di semua kalangan. Dimana untuk melihat bagaimana suatu pemerintah desa atau nagari dalam membentuk pembangunan dan pemberdayaan masyarakat yang lebih baik dari sebelumnya. Hal ini disebabkan semenjak implementasi UndangUndang Nomor 6 Tahun 2014 tentang Desa, desa memperoleh sumber pendapatan baru melalui Dana Desa (DD) yang berasal dari Anggaran Pendapatan Belanja Negara (APBN). Tidak hanya dari APBN desa juga memperoleh dana dari sumber pendapatan lainnya, besarannya meningkat setiap tahun sehingga sekarang rata-rata desa mengelola \pm 1 Miliar. Prioritas penggunaan dana desa terdapat dalam 2 bentuk program kegiatan diantaranya pembangunan fisik dan pemberdayaan masyarakat.

Menurut Sujarto (1985:12) aspek pembangunan fisik merupakan perwujudan nyata suatu tuntutan kebutuhan yang disebabkan oleh pertumbuhan dan perkembangan kegiatan sosial serta budaya. Menurut
B.S Muljana (2001:3) pembangunan fisik merupakan pembangunan yang dilaksanakan oleh pemerintah umumnya yang bersifat infrastruktur atau prasarana, yaitu bangunan fisik ataupun lembaga yang mempunyai kegiatan lain dibidang ekonomi, sosial budaya, politik dan pertahanan keamanan.

Menurut Susantyo (2007:5) pemberdayaan masyarakat adalah peningkatan kemandirian rakyat berdasarkan kapasitas dan kekuatan internal rakyat atas SDM baik material maupun non material melalui redistribusi modal. Pasal 7 Peraturan Menteri Desa, Pembangunan Daerah Tertinggal, dan Transmigrasi RI Nomor 4 Tahun 2017 tentang Penetapan Prioritas Penggunaan Dana Desa yaitu dana desa digunakan untuk membiayai program dan kegiatan bidang pemberdayaan masyarakat desa yang ditujukan untuk meningkatkan kapasitas.

Begitu banyaknya dana desa yang harus dikelola serta tidak adanya mekanisme check and balance akan membuka potensi korupsi oleh eksekutif desa. Setiap tahun pemerintah pusat telah 
menganggarkan dana desa yang cukup besar untuk diberikan kepada desa. Pada tahun 2015 sampai 2018 dana desa yang diberikan terus mengalami peningkatan hingga menjadi Rp 60 Triliun dengan rata-rata setiap desa sebesar \pm 800 juta. Hal ini dapat dilihat pada Tabel 1 mengenai rincian dana Provinsi Sumatera Barat Tahun 2015-2018. Selain itu, jumlah nagari yang ada di Sumatera Barat terus mengalami peningkatan melalui proses pemekaran nagari yang bertujuan untuk meningkatkan pelayanan publik di setiap desa.

Tabel 1

Rincian Dana Desa Provinsi Sumatera Barat Tahun 2015-2018

\begin{tabular}{|l|c|c|c|c}
\hline \multicolumn{1}{|c|}{ Rincian Alokasi } & $\mathbf{2 0 1 5}$ & $\mathbf{2 0 1 6}$ & $\mathbf{2 0 1 7}$ & $\mathbf{2 0 1 8}$ \\
\hline ADD (Alokasi Dana Desa) & 855,51 & 917,06 & 914,38 & 898,59 \\
\hline $\begin{array}{l}\text { Bagi Hasil PDRD (Pajak Daerah } \\
\text { dan Retribusi Daerah) }\end{array}$ & 28,56 & 27,56 & 30,18 & 30,39 \\
\hline Dana Desa & 267 & 598,64 & 796,54 & 790,08 \\
\hline Jumlah Desa & 880 & 880 & 928 & 928 \\
\hline Rata-rata Pendapatan Per Desa & $1,308 \mathrm{M}$ & $1,754 \mathrm{M}$ & $1,876 \mathrm{M}$ & $1,852 \mathrm{M}$ \\
\hline Rata-rata Dana Desa Per Desa & 303,4 juta & 680,3 juta & 858,3 juta & 851,4 juta \\
\hline
\end{tabular}

www.djpk.kemenkeu.go.id

$$
\text { Kabupaten Tanah Datar }
$$

merupakan salah satu kabupaten yang berhasil dalam pelaksanaan pembinaan keuangan desa melalui Perbup Tanah Datar Nomor 44 Tahun 2015 Tentang Pedoman Tata Cara Pengadaan Barang/Jasa di Nagari, Perbup Nomor 14 Tahun 2015 Tentang Besaran Alokasi Dana Nagari di Kabupaten Tanah Datar sampai Peraturan Bupati Nomor 17 Tahun 2017 Tentang Pedoman Teknis Prioritas Penggunaan Dana NagariTahun 2017. Pada tahun 2017, Kabupaten Tanah Datar mendapatkan alokasi dasar sebesar Rp.54.033.150 juta dan alokasi formula sebesar Rp.8.430.022 juta seperti yang tertera pada tabel berikut ini:
Tabel 2

Rincian Dana Desa Tahun Anggaran 2017 Menurut Kabupaten/Kota

\begin{tabular}{|c|c|c|c|c|c|c|}
\hline \multirow[t]{2}{*}{ No } & \multirow[t]{2}{*}{ Nama Daerah } & \multirow{2}{*}{$\begin{array}{c}\text { Jumlah } \\
\text { Desa }\end{array}$} & \multicolumn{2}{|c|}{ Alokasi Dasar } & \multirow{2}{*}{$\begin{array}{c}\text { Alokasi } \\
\text { Formula }\end{array}$} & \multirow[t]{2}{*}{ Ju } \\
\hline & & & Per Desa & Per Kab/Kota & & \\
\hline 1 & $\begin{array}{l}\text { Kab. Limapuluh } \\
\text { Kota }\end{array}$ & 79 & 720.442 & 56.914 .918 & 10.956 .200 & 67.8 \\
\hline 2 & Kab. Agam & 82 & 720.442 & 59.076 .244 & 11.695 .607 & 70.7 \\
\hline 3 & $\begin{array}{l}\text { Kab. Kepulauan } \\
\text { Mentawai }\end{array}$ & 43 & 720.442 & 30.979 .006 & 10.640 .393 & 41.0 \\
\hline 4 & $\begin{array}{l}\text { Kab. Padang } \\
\text { Pariaman }\end{array}$ & 103 & 720.442 & 74.205 .526 & 10.439 .202 & 84.6 \\
\hline 5 & Kab. Pasaman & 37 & 720.442 & 26.656 .354 & 9.294 .457 & 35.9 \\
\hline 6 & $\begin{array}{l}\text { Kab. Pesisir } \\
\text { Selatan }\end{array}$ & 182 & 720.442 & 131.120 .444 & 12.785 .510 & 143. \\
\hline 7 & Kab. Sijunjung & 61 & 720.442 & 43.546 .562 & 7.682 .966 & 51.6 \\
\hline 8 & Kab. Solok & 74 & 720.442 & 53.321 .708 & 10.769 .430 & 64.0 \\
\hline 9 & Kab. Tanah Datar & 75 & 720.442 & 54.033 .150 & 8.430 .022 & 62.4 \\
\hline 10 & Kota Sawah Lunto & 27 & 720.442 & 19.451 .934 & 4.213 .927 & 23.6 \\
\hline 11 & Kota Pariaman & 55 & 720.442 & 39.624 .310 & 4.524 .363 & 44.1 \\
\hline 12 & $\begin{array}{l}\text { Kab. Pasaman } \\
\text { Barat }\end{array}$ & 19 & 720.442 & 13.688 .393 & 11.564 .985 & 25.2 \\
\hline 13 & Kab. Dharmasra & 52 & 720.442 & 37.462 .984 & 7.635 .247 & $45 . \mathrm{C}$ \\
\hline \multirow[t]{2}{*}{14} & Kab. Solok Selatan & 39 & 720.442 & 28.097 .233 & 7.329 .886 & 35.4 \\
\hline & $\begin{array}{l}\text { Total Sumatera } \\
\text { Barat }\end{array}$ & 928 & 720.442 & 668.570 .176 & 127.968 .795 & 796. \\
\hline
\end{tabular}

Sumber:www.djpk.depkeu.go.id

Nagari Sungai Tarab adalah salah satu nagari di Kabupaten Tanah Datar yang memiliki kewenangan dalam mengelola dana desa sejak tahun 2015 guna mewujudkan pengelolaan keuangan desa yang baik dan transparan terhadap masyarakat. Dana desa terbukti telah menghasilkan sarana/prasarana yang bermanfaat bagi masyarakat desa tersebut seperti bidang pelaksanaan pembangunan nagari, bidang pemberdayaan masyarakat dan lain-lain. Pengelolaan keuangan dana desa di nagari Sungai Tarab masih belum mencukupi kebutuhan masing-masing jorong. Serta adanya prokontra di tengah masyarakat terhadap manfaat dana desa yang terlihat lebih kearah pelaksanaan pembangunan nigari jika dibandingkan dengan bidang pemberdayaan masyarakat. Dalam hal ini terkait dengan banyaknya dana yang dihabiskan dalam bidang pembangunan. Berdasarkan wawancara penulis dengan sekretaris Nagari Sungai Tarab Syufrihadi 
mengatakan dalam bidang pemberdayaan masyarakat tidak seberapa yang dijalankan oleh nagari, disebabkan wilayah nagari Sungai Tarab ini lebih luas jika dibandingkan dengan nagari lain. Selain itu jumlah kader yang memberikan penyuluhan di bidang pemberdayaan masyarakat juga masih kurang (tanggal 28 Mei 2019)."

Dalam hal perencanaan penggunaan dana desa, sering terjadi keterlambatan dan masyarakat di tingkat jorong hanya sedikit yang menghadiri musyawarah perencanaan tersebut. Hal ini mengakibatkan banyak masyarakat yang kurang mendapatkan informasi alokasi dana desa dan tidak mengetahui kegiatankegiatan pembangunan yang dilakukan oleh pemerintah nagari yang menggunakan dana desa. Penerimaan dana desa di Nagari Sungai Tarab tahun 2018 mengalami pengurangan sehingga mengakibatkan munculnya kendala baru. Dalam setiap proses pengelolaan dana desa dari tahap perencanaan, pelaksanaan, penatausahaan, pelaporan dan pertanggung jawaban harus sesuai dengan Permendagri No. 113 Tahun 2014 tentang Pengelolaan Dana Desa. Berdasarkan paparan permasalahan diatas jelas bahwa masih ada permasalahan terkait dengan pengelolaan dana desa dan respon masyarakat terhadap manfaat dana desa.

\section{METODE PENELITIAN}

Penelitian ini menggunakan pendekatan kualitatif deskriptif. Penentuan informan menggunakan teknik purposive sampling. Informan penelitian diantaranya tokoh masyarakat, kepala desa dan masyarakat Nagari Sungai Tarab. Informan diharapkan yang paham dan terkait langsung dengan permasalahan penelitian guna memperoleh data dan informasi yang lebih akurat. Teknik yang digunakan adalah wawancara dan studi dokumentasi. Setelah data terkumpul, diolah dengan teknik analisis data yaitu reduksi data, penyajian data dan penarikan kesimpulan dengan melakukan verifikasi. Untuk menguji keabsahan data yang diperoleh dalam penelitian ini, digunakan teknik triangulasi data dengan tujuan menguji kepercayaan terhadap data hasil suatu penelitian. Metode triangulasi menurut Sugiyono (2012: 125) adalah metode yang yang mengecek keabsahan data yang memanfaatkan sesuatu yang lain. Dalam penelitian ini, peneliti menggunakan teknik triangulasi data yang membandingkan hasil wawancara dengan informan, dengan kondisi rill di lapangan.

\section{HASIL DAN PEMBAHASAN}

Berdasarkan Permendagri Nomor 4 Tahun 2007 Pasal 1 disebutkan bahwa yang dimaksud dengan pengelolaan adalah rangkaian kegiatan yang diawali dengan tahap perencanaan, pengadaan, penggunaan, penatausahaan, penilaian, pembinaan, pengawasan dan pengendalian. Kemudian menurut PP No. 8 Tahun 2016 tentang dana desa Pasal 1 ayat 2 menyatakan dana desa adalah dana yang bersumber dari APBN yang diperuntukan bagi desa yang disalurkan melalui APBD Kabupaten/Kota dan digunakan untuk membiayai penyelenggaraan pemerintahan, pelaksanaan pembangunan, pembinaan kemasyarakatan dan pemberdayaan 
masyarakat. Prioritas penggunaan dana desa terbagi dalam 2 (dua) bentuk program diantaranya:

1) Pembangunan Fisik

Merupakan perwujudan nyata dari pembangunan segi-segi non fisik yang meliputi sosial budaya, sosial ekonomi dan sebagainya. Menurut B.S Muljana (2001: 3) pembangunan fisik merupakan pembangunan yang dilaksanakan oleh pemerintah umumnya yang bersifat infrastruktur atau prasarana, yaitu bangunan fisik ataupun lembaga yang mempunyai kegiatan lain dibidang ekonomi, sosial budaya, politik dan pertahanan keamanan. Pembangunan fisik haruslah menggunakan sumber daya alam yang terdapat di masing-masing daerah.

\section{Tabel 3}

Daftar Realisasi Penggunaan Dana Desa Tahun 2017

\begin{tabular}{|c|c|c|c|}
\hline No. & Jenis Prasarana & Volume & Jumlah Dan \\
\hline 1 & $\begin{array}{l}\text { Rabat Beton dan Pemasangan TPT jalan Binuang } \\
\text { ke Luak Gadang }\end{array}$ & $175 \mathrm{M}$ & 35.308 .410 \\
\hline 2 & $\begin{array}{l}\text { Rabat Beton dan Pemasangan TPT Jalan Usaha } \\
\text { Tani Biaro }\end{array}$ & $125 \mathrm{~m}$ & 90.450 .700 \\
\hline 3 & $\begin{array}{l}\text { Rabat Beton dan Pemasangan TPT Jalan Sebelah } \\
\text { Air ke Pantau }\end{array}$ & & 105.197 .000 \\
\hline 4 & Pencoran Jalan Subarang ke Ateh Luang & & 54.838 .700 \\
\hline 5 & $\begin{array}{l}\text { Rabat Beton dan Pemasangan TPT Jalan Batu } \\
\text { tagak }\end{array}$ & $205 \mathrm{M}$ & 91.316 .500 \\
\hline 6 & $\begin{array}{l}\text { Rabat beton dan Pemasangan TPT Jalan Luak } \\
\text { Godang ke Pandam }\end{array}$ & $175 \mathrm{M}$ & 58.826 .416 \\
\hline 7 & $\begin{array}{l}\text { Rabat Beton dan Pemasangan TPT Jalan Melayu } \\
\text { ke Mandahiliang }\end{array}$ & & 60.908 .700 \\
\hline 8 & Rabat Beton Pemasangan TPT Jalan Bulaan & & 31.183 .700 \\
\hline 9 & Lanjutan Pencoran Jalan Kincia Kopi & $50 \mathrm{M}$ & 4.762 .000 \\
\hline 10 & Irigasi Bandar Sawah & $250 \mathrm{M}$ & 68.109 .300 \\
\hline & & & 261.692 .911 \\
\hline
\end{tabular}

Sumber: Data base Nagari Sungai

Tarab

Terkait dengan tabel 3 di atas, terlihat bahwa prioritas penggunaan dana desa di Nagari Sungai Tarab lebih mengarah kepada pembangunan fisik atau infrastruktur yang berperan penting dalam penggerak pertumbuhan ekonomi masyarakat. Berdasarkan penelitian yang peneliti lakukan di Nagari Sungai Tarab menunjukkan bahwa penggunaan dana desa lebih banyak diperuntukkan bagi pembangunan fisik jika dibandingkan dengan pemberdayaan masyarakat. Dalam hal ini dapat dilihat dari realisasi pembangunan pencoran Jalan Ladang Koto, Pendaman Jalan Binuang, jalan ateh Guguak, jalan gang parak gatah, jalan usaha tani Bodi dan lain sebagainya. Dalam pelaksanaan pembangunan fisik yang dilakukan oleh pemerintah Nagari Sungai Tarab juga mempertimbangkan hal-hal seperti dana yang ada, waktu pelaksanaan, lokasi, keuntungan dan daya guna untuk masyarakat Nagari Sungai Tarab. Diharapkan kepada masyarakat untuk menjaga dan merawat fasilitasfasilitas yang sudah dibangun tersebut agar bisa tahan lama.

\section{2) Pemberdayaan Masyarakat}

Pemberdayaan masyarakat adalah proses pembangunan di mana masyarakat berinisiatif untuk memulai proses kegiatan sosial untuk memperbaiki situasi dan kondisi diri sendiri. Pemberdayaan masyarakat hanya bisa terjadi apabila masyarakat itu sendiri ikut berpartisipasi. Menurut Sujarto (2007:5) pemberdayaan masyarakat adalah peningkatan kemandirian rakyat berdasarkan kapasitas dan kekuatan internal rakyat atas SDM baik material maupun nonmaterial melalui redistribusi modal. 
Tabel 4 Daftar Realisasi Penggunaan Dana Desa Tahun 2017

\begin{tabular}{|l|l|c|r|}
\hline No. & \multicolumn{1}{|c|}{ Jenis Kegiatan } & Volume & \multicolumn{1}{c|}{ Jumlah Dana } \\
\hline 1 & Pelatihan Industri Rumah Tangga & 1 paket & 9.616 .000 \\
\hline 2 & Pelatihan Kader Tekhnis & 1 paket & 10.350 .000 \\
\hline 3 & Pelatihan perbengkelan & 1 paket & 73.509 .704 \\
\hline 4 & Sosialisasi Posyantek & 1 paket & 4.817 .200 \\
\hline 5 & Pelatihan Dasa Wisma & 1 paket & Silfa \\
\hline 6 & Peltihan Penyelenggaraan Jenazah & 1 paket & Silfa \\
\hline 7 & Pelatihan Manajemen dakwah remaja mesjid & 1 paket & Silfa \\
\hline 8 & Lanjutan pelatihan khatib jumat & 1 paket & 6.124 .000 \\
\hline 9 & Pelatihan Pengelola BUMNag & 1 paket & 11.000 .000 \\
\hline 10 & Sosialsiasi Nagari Sehat & 1 paket & 2.689 .000$. \\
\hline 11 & Penyertaan Modal BUMNag & 1 paket & 100.000 .000 \\
\hline & Jumlah & & $\mathbf{2 1 8 . 1 0 5 . 9 0 4}$ \\
\hline
\end{tabular}

Sumber: Data base Nagari Sungai Tarab

Terkait dengan tabel 4 diatas, terlihat bahwa Pemerintah nagari Sungai Tarab melalui penggunaan dana desa telah menganggarkan program kegiatan di bidang pemberdayaan masyarakat yang bertujuan untuk mengembangkan kemampuan dan kemandirian masyarakat nagari agar melepaskan diri dari kemiskinan dan keterbelakangan. Dalam hal kegiatan pemberdayaan masyarakat yang dilakukan pemerintah nagari masih ada yang tidak terjalankan atau disentuh nagari yang disebabkan karena kekurangan ahli dalam pemberian pelatihan dan kondisi geografis yang cukup luas dibanding nagari lain.

\section{Berdasarkan Permendagri} Nomor 4 Tahun 2007 Pasal 1 bahwa yang dimaksud dengan pengelolaan adalah rangkaian kegiatan yang diawali dengan tahap perencanaan, pengadaan, penggunaan, penatausahaan, penilaian, pembinaan, pengawasan dan pengendalian. Jadi pengeloaan dapat diartikan sebagai keseluruhan kegiatan dalam melakukan suatu pekerjaan atau kegiatan. Pengelolaan dana desa di Nagari Sungai Tarab berpedoman pada Permendagri Nomor 113 Tahun 2014 tentang Pengelolaan Dana Desa dan Peraturan Bupati Tanah Datar Nomor 14 Tahun 2015 serta Peraturan Bupati Tanah Datar Nomor 44 Tahun 2015.

Gambaran umum pengelolaan keuangan desa dapat dilaksanakan dengan baik dan harus didukung oleh sumberdaya manusia yang kompeten dan berkualitas agar bisa memajukan desa serta sistem dan prosedur keuangan yang memadai. Menurut Permendagri Nomor 113 Tahun 2014 tentang Pengelolaan Keuangan Desa, terdapat lima tahap dalam melakukan pengelolaan keuangan desa yang bauik yaitu perencanaan, pelaksanaan, penatausahaan, pelaporan dan pertanggungjawaban.

Terkait dengan pengelolaan dana desa di Nagari Sungai Tarab masih mengalami beberapa kendala diantaranya dalam tahap perencanaan, yang dimulai dengan musyawarah Jorong yang dilakukan di masingmasing jorong di Nagari Sungai Tarab masih banyak masyarakat yang tidak hadir. Kemudian pelaksanaan Musrembang hanya mengundang lembaga unsur pemerintah, tokoh masyarakat dengan memberi uang transpor, makan dan minum. Tahap pelaksanaan, akan sukses apabila suatu nagari memiliki sumber daya manusia yang kompeten dan menguasai sistem dalam pengimputan data penggunaan dana desa. Namun Nagari Sungai Tarab masih kurang ahli dalam teknis hanya berdasarkan perkiraan saja.

Pada tahap penatausahaan, bendahara adalah bagian terpenting dalam pengurusan pencatatan setiap penerimaan, pengeluaran dan 
melakukan tutup buku setiap akhir bulan serta mempertanggung jawabkan semua penerimaan pendapatan nagari dan besaran pengeluaran pendapatan nagari dalam rangka pelaksanaan APBDesa.

Sedangkan pada tahap pelaporan dan pertanggungjawaban, proses pelaporan dalam pengelolaan dana desa yang dilakukan oleh pemerintah Nagari Sungai Tarab belum sesuai dengan Permendagri Nomor 113 Tahun 2014 Tentang Pengelolaan Keunagan Desa, diamana pemerintah nagari belum mampu melaporkan kegiatan sesuai dengan jadwal waktu yang telah ditentukan. Laporan realisasi dan laporan pertanggungjawaban realisasi pelaksanaan APBDesa langsung dilaporkan oleh Wali Nagari Sungai Tarab kepada Bupati dan bersifat mutlak. Terkait dengan laporan realisasi dan laporan pertanggungjawaban realisasi pelaksanaan APBDesa diinformasikan kepada masyarakat secara tertulis dan dengan media informasi yang mudah diakses oleh masyarakat, seperti papan informasi. Namun nayatanya hal tersebut tidak diinformasikan kepada masyarakat.

Respon Masyarakat Terhadap Manfaat Dana Desa Di Nagari Sungai Tarab

Pembangunan dan pemberdayaan masyarakat adalah prioritas yang jelas dari penggunaan dana desa guna untuk mewujudkan desa atau nagari menjadi mandiri dalam berbagai bidang kehidupan. Dengan adanya pembangunan dan pemberdayaan masyarakat, terdapat berbagai tanggapan yang diberikan masyrakat terhadap manfaat dari dana desa. Nagari Sungai Tarab telah menjalankan program pembangunan dan pemberdayaan dengan semaksimal mungkin. Terkait dengan respon manfaat beberapa kalangan yang mengatakan bermanfaat dalam bidang pembangunan infrastruktur dimana terdapat respon yang baik terhadap bidang pembangunan karena masyarakat merasa terbantu dengan adanya infrastruktur yang mempermudah akses keluar masuk kampung dan aktifitas sehari-hari masyarakat secara umum seperti pembuatan irigasi bandar sawah, pembuatan jalan usaha tani, pencoran dan pendaman jalan. Namun berbanding terbalik dengan bidang pemberdayaan masyarakat, dimana Pemerintah Nagari Sungai Tarab masih belum berhasil sepenuhnya melaksanakan program pemberdayaan dikarenakan luas wilayah dan kekurangan tenaga penyuluh. Masyarakat membutuhkan adanya program kegiatan yang dapat menambah wawasan dan pengetahuan untuk memperbaiki dan meningkatkan ekonomi masyarakat nagari.

\section{KESIMPULAN}

Berdasarkan uraian hasil penelitian yang telah peneliti kemukakan tentang dana desa dan respon masyarakat terhadap manfaat dana desa di Nagari Sungai Tarab. Pengelolaan dana desa di Nagari Sungai Tarab masih mengalami beberapa kendala seperti terlambatnya musyawarah perencanaan pembangunan ditambah dengan rendahnya tingkat partisipasi masyarakat dalam menghadiri, program kegiatan lebih didominasi dengan pembangunan fisik, swadaya masyarkat yang kurang terhadap pembangunan yang sudah dibuat, 
serta sumber daya manusia yang kurang memahami penggunaan dana desa.

Terkait dengan respon masyarakat terhadap manfaat dana desa di Nagari Sungai Tarab, dimana masyarakat merasa terbantu dengan adanya infrastruktur yang mempermudah akses keluar masuk kampung dan aktifitas sehari-hari masyarakat secara umum seperti pembuatan irigasi sawah, pembuatan jalan usaha tani, pencoran dan pendaman jalan. Namun berbanding terbalik dengan bidang pemberdayaan masyarakat, dimana Pemerintah Nagari masih belum berhasil sepenuhnya melaksanakan program pemberdayaan dikarenakan luas wilayah dan kekurangan tenaga penyuluh. Masyarakat membutuhkan adanya program kegiatan yang dapat menambah wawasan dan pengetahuan untuk memperbaiki dan meningkatkan ekonomi masyarakat nagari.

\section{DAFTAR PUSTAKA}

Kementrian Keuangan Republik Indonesia. (2017). Buku Pintar Dana Desa (Dana Desa Untuk Kesejahteraan Masyarakat)

Sugiyono, (2012). Metode Penelitian Kualitatif Dan R\&D. Bandung: Alfabeta

Sujarto, Djoko (1985). Beberapa pengertian tentang Perencanaan Fisik. Jakarta: Bharatara Karya Aksara

Muljana, B.S. 2001. Perencanaan Pembangunan Nasional, Proses Penyusunan Rencana Pembangunan Nasional dengan Fokus Repelita V. Jakarta: UI

Susantyo, 2007. Partisipasi Masyarakat Dalam Pembnagunan
Pembesaan, telaah

atas tulisan David C. Korten. Jurnal Sosio Informa Vol 12 No. 3

PP No. 8 Tahun 2016 tentang Dana Desa

Peraturan Menteri Dalam Negeri No 113 Tahun 2014 Tentang Pengelolaan Keuangan

Desa

Undang-undang No. 6 tahun 2014 tentang desa

Undang-Undang no. 32 Tahun 2004 tentang Daerah 